\title{
THE EFFECTS OF A LEUKOCYTE-DEPLETING FILTER ON CEREBRAL AND RENAL RECOVERY AFTER DEEP HYPOTHERMIC CIRCULATORY ARREST
}

Stephen M. Langley, MD, FRCS

Paul J. Chai, MD

Steven S. Tsui, MD, FRCS

James J. Jaggers, MD

Ross M. Ungerleider, MD
Objective: The purpose of this study was to determine the effects of a leukocyte-depleting filter on cerebral and renal recovery after deep hypothermic circulatory arrest.

Methods: Sixteen 1-week-old piglets underwent cardiopulmonary bypass, were cooled to $18^{\circ} \mathrm{C}$, and underwent 60 minutes of circulatory arrest, followed by 60 minutes of reperfusion and rewarming. Global and regional cerebral blood flow, cerebral oxygen metabolism, and renal blood flow were determined before cardiopulmonary bypass, after the institution of cardiopulmonary bypass, and at 1 hour of deep hypothermic circulatory arrest. In the study group ( $\mathrm{n}=8$ piglets), a leukocyte-depleting arterial blood filter was placed in the arterial side of the cardiopulmonary bypass circuit.

Results: With cardiopulmonary bypass, no detectable change occurred in the cerebral blood flow, cerebral oxygen metabolism, and renal blood flow in either group, compared with before cardiopulmonary bypass. In control animals, after deep hypothermic circulatory arrest, blood flow was reduced to all regions of the brain $(P<.004)$ and the kidneys $(P=.02)$, compared with before deep hypothermic circulatory arrest. Cerebral oxygen metabolism was also significantly reduced to $60.1 \% \pm 11.3 \%$ of the value before deep hypothermic circulatory arrest $(P=.001)$. In the leukocyte-depleting filter group, the regional cerebral blood flow after deep hypothermic circulatory arrest was reduced, compared with the value before deep hypothermic circulatory arrest $(P<.01)$. Percentage recovery of cerebral blood flow was higher in the leukocyte filter group than in the control animals in all regions but not significantly so $(P>.1)$. The cerebral oxygen metabolism fell to $66.0 \% \pm 22.3 \%$ of the level before deep hypothermic circulatory arrest, which was greater than the recovery in the control animals but not significantly so $(P=.5)$. After deep hypothermic circulatory arrest, the renal blood flow fell to $81.0 \% \pm 29.5 \%$ of the value before deep hypothermic circulatory arrest $(P=.06)$. Improvement in renal blood flow in the leukocyte filter group was not significantly greater than the recovery to $70.2 \% \pm 26.3 \%$ in control animals $(P=.47)$.

Conclusions: After a period of deep hypothermic circulatory arrest, there is a significant reduction in cerebral blood flow, cerebral oxygen metabolism, and renal blood flow. Leukocyte depletion with an in-line arterial filter does not appear to significantly improve these findings in the neonatal piglet. (J Thorac Cardiovasc Surg 2000;119:1262-9)
From the Department of Pediatric Cardiac Surgery, Duke University Medical Center, Durham, NC.

Received for publication April 22, 1999; revisions requested July 19, 1999; revisions received Dec 17, 1999; accepted for publication Dec 17, 1999.

Address for reprints: Stephen Langley, MD, Department of Cardiothoracic Surgery, Southampton General Hospital, Southampton, Hampshire, SO16 6YD, United Kingdom (E-mail: StephenLangley@dial.pipex.com).

Copyright $\odot 2000$ by The American Association for Thoracic Surgery $0022-5223 / 2000 \$ 12.00+0 \quad \mathbf{1 2 / 1 / 1 0 5 6 3 8}$

doi: $10.1067 / \mathrm{mtc} .2000 .105638$
Athough neutrophils were first seen in human cereA bral infarcts over 10 years ago, ${ }^{1,2}$ it is only recently that their contribution to reperfusion brain injury has been appreciated. Neutrophils are usually the first exogenous cells to infiltrate the ischemic brain. They contribute to the development of ischemia by increasing capillary plugging, reducing cerebromicrovascular blood flow, and increasing vascular permeability. ${ }^{3,4}$ In addition, neutrophils infiltrate the brain parenchyma and damage neurons and glial cells. Neutrophil secre- 
tion of oxygen-derived free radicals, cytokines, proteases, and lipid-derived mediators such as arachidonic acid and leukotrienes contributes to the cerebral injury that results from a period of cerebral ischemia and reperfusion.

The importance of neutrophils in cerebral ischemic damage began to emerge after studies in the early 1990s, which showed a reduction in neuronal injury after ischemia in neutropenic animals. Immunodepletion of neutrophils can reduce the cerebral infarct size after middle cerebral artery occlusion. ${ }^{5,6}$ In addition, neutropenia, which is caused by monoclonal antineutrophil serum, results in significantly reduced cerebral edema after cerebral ischemia. ${ }^{6,7}$ Other studies have shown improved cerebral blood flow (CBF) and reduced neurologic deficit with neutropenia. ${ }^{5}$

A variety of different leukocyte-depleting blood filters have been used in various experimental models in an attempt to modulate the effects of activated leukocytes after cardiopulmonary bypass (CPB). One such leukocyte-depleting filter is the LeukoGuard 6 (LG6; Pall Biomedical Products Corporation, East Hills, NY). The LG6 filter consists of a $40-\mu \mathrm{m}$ screen filter for removal of microaggregates and an autoventing gross and micro air-separating chamber. In addition it contains a depth filter of nonwoven polyester fiber to remove leukocytes. Previous studies with the LG6 filter (with bovine blood) have shown a $50 \%$ total leukocyte reduction and a $70 \%$ neutrophil depletion rate over a 90 -minute perfusion period with both pulsatile ${ }^{8}$ and nonpulsatile ${ }^{9}$ perfusion. In another study during 1 hour of simulated $\mathrm{CPB}$, the mean reduction in white cell count across the filter was $45 \%$, and the reduction of neutrophils was $70 \%$. Furthermore, the filter diminished the average expression of cellular markers for neutrophil activation (ie, CD11b, CD45Ro, CD67, and Lselectin) by approximately $20 \%$ after 1 hour of CPB, compared with the control animals. ${ }^{10}$

There are no previously reported studies in which markers of acute cerebral impairment have been used to investigate the effects of leukocyte depletion during CPB. It is now well established that neutrophils contribute to injury that results from cerebral ischemia. The aim of the current study was to determine the effects of an LG6 filter on cerebral and renal recovery after deep hypothermic circulatory arrest (DHCA). The null hypothesis for this study is that incorporation of an in-line LG6 filter in the arterial side of the CPB circuit does not affect $\mathrm{CBF}$ and metabolism or renal blood flow (RBF) after 60 minutes of DHCA in the neonatal piglet.

\section{Methods}

Animal preparation. All animal experiments were conducted with the approval of the institution's Animal Care and Use Committee. The animals received humane care in compliance with the "Guide for the Care and Use of Laboratory Animals" published by the National Institutes of Health (NIH publication 85-23, revised 1995) and were housed in the institution's NIH-approved animal facility before the experiments.

Sixteen neonatal piglets (aged, 1-2 weeks; weight, $2.3 \pm$ $0.1 \mathrm{~kg}$ [mean \pm SEM]) were anesthetized with an intramuscular injection of ketamine $\left(50 \mathrm{mg} \cdot \mathrm{kg}^{-1}\right)$ and acepromazine $\left(15 \mu \mathrm{g} \cdot \mathrm{kg}^{-1}\right)$. Intravenous methylprednisolone $\left(30 \mathrm{mg} \cdot \mathrm{kg}^{-1}\right)$ was administered through a 24-gauge cannula in the marginal vein of the pinna. Orotracheal intubation was performed, and mechanical ventilation (Infant Ventilator; Sechrist Industries, Anaheim, Calif) was commenced to achieve arterial oxygen tensions of 150 to $250 \mathrm{~mm} \mathrm{Hg}$ and carbon dioxide tensions of 35 to $45 \mathrm{~mm} \mathrm{Hg}$. The animals were paralyzed with intravenous pancuronium $\left(300 \mu \mathrm{g} \cdot \mathrm{kg}^{-1}\right)$ and anesthetized with fentanyl $\left(100 \mu \mathrm{g} \cdot \mathrm{kg}^{-1}\right)$. Thereafter, anesthesia was maintained with a continuous infusion of fentanyl $(25 \mu \mathrm{g}$ $\left.\cdot \mathrm{kg}^{-1} \cdot \mathrm{h}^{-1}\right)$. An 18-gauge cannula was placed in the descending aorta through the femoral artery for blood pressure monitoring and arterial blood sampling. The animal's temperature was monitored throughout the study by an indwelling nasopharyngeal temperature probe (Yellow Springs Instrument Co, Inc, Yellow Springs, Ohio). Temperature was maintained at $36^{\circ} \mathrm{C}$, except for the period of induced hypothermia. The heart was exposed through a median sternotomy. Cardiac instrumentation consisted of the insertion of a 3F micromanometer (Millar Instruments Inc, Houston, Tex) into the superior vena cava for central venous pressure monitoring, the insertion of a 22-gauge plastic catheter into the left atrium through the left atrial appendage, and the placement of an 8-mm flow probe (Transonic Systems, Ithaca, NY) around the proximal pulmonary artery for cardiac output monitoring.

Sagittal sinus access. The animals were anticoagulated with intravenous heparin $(500 \mathrm{IU} / \mathrm{kg})$ before the sagittal sinus was accessed. A 1-cm strip of scalp was raised in the midline over the vertex of the skull. Two separate 2-mm burr holes were made over the superior sagittal sinus for repeated sagittal sinus venous blood sampling and continuous sagittal sinus venous pressure monitoring with a $3 \mathrm{~F}$ micromanometer (Millar Instruments Inc).

CPB and circulatory arrest. An $8 \mathrm{~F}$ arterial cannula and a $20 \mathrm{~F}$ venous cannula (DLP Inc, Grand Rapids, Mich) were inserted through purse-string sutures into the ascending aorta and the right atrium, respectively. CPB was commenced at a flow rate of $120 \mathrm{~mL} \cdot \mathrm{kg}^{-1} \cdot \mathrm{min}^{-1}$. The pump-oxygenator system consisted of a nonpulsatile roller pump (Sarns/3M, Ann Arbor, Mich) and a hollow-fiber membrane oxygenator (Medtronic Minimax PLUS; Medtronic Inc, Anaheim, Calif). The circuit was primed with heparinized fresh blood from a donor pig. Ringer lactate and sodium bicarbonate solutions 
were added to the prime to achieve a hematocrit value of 0.25 and a $\mathrm{pH}$ of 7.4 at $37^{\circ} \mathrm{C}$. The total prime volume was approximately $450 \mathrm{~mL}$. The temperature of the perfusate was controlled with the integral heat exchanger in the venous reservoir of the oxygenator and a water bath system (BIO-CAL 370; Medtronic Bio-Medicus, Minneapolis, Minn). Animals were cooled to a temperature of $18^{\circ} \mathrm{C}$ over a standard duration of 20 minutes by the circulation of ice water through the heat exchanger. At the end of the cooling period, the circulation was arrested, and the animal was drained. DHCA was established, and the aortic and right atrial cannulas were clamped. After 60 minutes of DHCA, the aortic and venous cannulas were unclamped. Perfusion was re-established at $120 \mathrm{~mL} \cdot \mathrm{kg}^{-1} \cdot \mathrm{min}^{-1}$, with the perfusate initially at room temperature $\left(20^{\circ} \mathrm{C}-22^{\circ} \mathrm{C}\right)$. Rewarming was accomplished by circulating warm water to the heat exchanger in the venous reservoir. A nasopharyngeal temperature of $36^{\circ} \mathrm{C}$ was generally reached by 45 minutes of reperfusion. During cooling and rewarming, blood gases were managed according to the alpha-stat strategy. The arterial $\mathrm{pH}$ was maintained at 7.35 to 7.45 , and carbon dioxide tension was maintained at 35 to 45 $\mathrm{mm} \mathrm{Hg}$, measured at $37^{\circ} \mathrm{C}$ and uncorrected for the temperature of the animal. Arterial oxygen tension was kept between 150 and $250 \mathrm{~mm} \mathrm{Hg}$, and hematocrit level was kept between 0.23 and 0.28 . Sodium bicarbonate $(8.4 \%)$ was given when necessary but not immediately before CBF measurements. At the end of the study, the animals were killed by a bolus injection of fentanyl and cessation of CPB.

Measurement of CBF. CBF measurements were determined by the reference-sample, radiolabeled microsphere technique ${ }^{11}$ during $\mathrm{CPB}$ at $36^{\circ} \mathrm{C}$. The technique described in the current study is similar to that used in previous reports from our laboratory. ${ }^{12,13}$ Suspensions of microspheres with a diameter of $15.5 \pm 0.1 \mu \mathrm{m}$ (DuPont de Nemours \& Co, Wilmington, Del) were made up in $10 \%$ dextran and $0.01 \%$ polysorbate 80 (TWEEN 80; ICI Americas Inc, Wilmington, Del) with $10^{6}$ microspheres per milliliter. Three different isotopes were used in each piglet $\left({ }^{46} \mathrm{Sc},{ }^{103} \mathrm{Ru}\right.$, and $\left.{ }^{95} \mathrm{Nb}\right)$. For each flow measurement, $10^{6}$ microspheres were injected into a side port of the arterial tubing $30 \mathrm{~cm}$ proximal to the aortic cannula over 30 seconds and washed through with $5 \mathrm{~mL}$ warm saline solution. A reference blood sample was withdrawn from the distal aorta at a constant rate of $3 \mathrm{~mL} \cdot \mathrm{min}^{-1}$ with a Harvard syringe pump (Harvard Apparatus, South Natick, Mass), commencing 10 seconds before the microsphere injection and continued for a total of 2 minutes. At the end of the experiment, the brain was removed and divided into left and right cerebral hemispheres, basal ganglia, cerebellum, and brain stem (midbrain, pons, and medulla oblongata). In addition, the kidneys were also removed for a determination of RBF. After measurement of fresh weights, the brain parts and kidneys were dissolved in $2 \mathrm{~mol} / \mathrm{L}$ potassium hydroxide solution and analyzed, together with the reference blood sample, in a gamma counter (Auto-Gamma 5530; Packard Instrument Co, Meriden, Conn) to estimate the quantity of each type of radiolabeled microsphere present in the specimen. The withdrawal rate of the reference blood sample and the ratio of counts from a brain part to the reference blood sample allowed calculation of regional CBF. $\mathrm{CBF}$ measurements are expressed in milliliters per 100 grams of brain per minute by normalizing for fresh tissue weight. The weighted sum of regional CBF allowed calculation of global CBF.

Cerebral perfusion pressure was taken as the difference between the mean arterial pressure and the sagittal sinus venous pressure. Cerebral vascular resistance (CVR) was the ratio of cerebral perfusion pressure to global CBF (in units of millimeters of mercury $\cdot 100 \mathrm{gm} \cdot \mathrm{min} \cdot \mathrm{mL}^{-1}$ ). Systemic vascular resistance was taken as the ratio between the systemic perfusion pressure and the total bypass pump flow rate (systemic vascular resistance $=[$ mean arterial pressure - right atrial pressure]/[pump flow rate] in units of millimeters of mercury $\left.\cdot 100 \mathrm{gm} \cdot \mathrm{min} \cdot \mathrm{mL}^{-1}\right)$.

Measurement of cerebral oxygen handling. Arterial and sagittal sinus blood samples were taken just before each microsphere injection for estimation of oxygen tension, carbon dioxide tension, oxygen saturation, $\mathrm{pH}$, and base excess with a GEM-Stat Blood Gas/Electrolyte Monitor (Mallinckrodt Sensor Systems Inc, Ann Arbor, Mich). Hemoglobin levels (in grams per deciliter) were measured from arterial blood samples (482 Co-Oximeter; Instrumentation Laboratory Corp, Lexington, Mass). Cerebral delivery of oxygen $\left(\mathrm{CDO}_{2}\right.$, in milliliters per $100 \mathrm{~g}$ of brain per minute), cerebral metabolic rate of oxygen $\left(\mathrm{CMRO}_{2}\right.$, in milliliters per $100 \mathrm{~g}$ of brain per minute), and cerebral oxygen extraction $\left(\mathrm{CEO}_{2}\right.$, as a percent) were calculated as follows: $\mathrm{CDO}_{2}=\mathrm{CBF} \times$ arterial oxygen content; $\mathrm{CMRO}_{2}=\mathrm{CBF} \times($ arterial oxygen content - sagittal sinus venous oxygen content $)$; and $\mathrm{CEO}_{2}=\left(\mathrm{CMRO}_{2} / \mathrm{CDO}_{2}\right) \times$ $100 \%$. The oxygen content (in units of milliliters of oxygen per milliliter of blood) was calculated by the following formula: oxygen content $=0.01 \times[(1.36)($ hemoglobin $)($ oxygen saturation $)+(0.003)$ (oxygen tension) $]$.

Experimental protocol and data collection. The animals were randomized into 2 groups, with 8 animals in each group. In the study group an LG6 leukocyte depletion arterial blood filter was placed in the arterial side of the $\mathrm{CPB}$ circuit before priming. The filter was sited distal to the membrane oxygenator and about 5 feet proximal to the aortic cannula. The control group underwent CPB without the use of a leukocytedepleting filter in the bypass circuit. In control animals an AutoVent-6 screen filter (Pall Biomedical Products Corporation) was used. This filter differs from the LG6 filter in that the depth filter of nonwoven polyester fiber for leukocyte removal is absent. All animals were cannulated for CPB, and at 20 minutes after the end of instrumentation, microspheres were injected through the left atrial catheter for the CBF measurement before CPB. After the collection of the reference blood sample, normothermic perfusion was commenced at $120 \mathrm{~mL} \cdot \mathrm{kg}^{-1} \cdot \mathrm{min}^{-1}$. Once the animals were stabilized, the pump flow rate was adjusted to provide and maintain a constant cerebral perfusion pressure of $50 \mathrm{~mm} \mathrm{Hg}$ for 15 minutes. The measurement before DHCA was performed; the pump flow rate was returned to $120 \mathrm{mg} \cdot \mathrm{kg}^{-1} \cdot \mathrm{min}^{-1}$, and the mean arterial pressure was allowed to drift. All the ani- 
mals were cooled to a nasopharyngeal temperature of $16^{\circ} \mathrm{C}$ to $18^{\circ} \mathrm{C}$ over 20 minutes. The circulation was arrested, and the animal was drained. After 60 minutes of DHCA, circulation was recommenced at $120 \mathrm{mg} \cdot \mathrm{kg}^{-1} \cdot \mathrm{min}^{-1}$, and the animal was rewarmed. After 45 minutes of rewarming, the pump flow rate was again adjusted to maintain a cerebral perfusion pressure of $50 \mathrm{~mm} \mathrm{Hg}$. When the animal had been rewarmed for a total of 60 minutes, the third $\mathrm{CBF}$ measurement was performed. Data collected at the 2 time points included nasopharyngeal temperature, mean arterial pressure, right atrial pressure, sagittal sinus venous pressure, arterial and sagittal sinus blood gases, CPB flow rate, electrolytes, hematocrit, hemoglobin, CBF, and RBF.

Statistical analysis. All results are reported as mean \pm SD. The results were entered into a Microsoft Excel 97 spreadsheet (Microsoft Corporation, Redmond, Wash) for further analysis. Repeating formulae calculated the mean and SEM for all data collected in each animal. Further repeating formulae were programmed for calculation of the $\mathrm{CBF}, \mathrm{CDO}_{2}, \mathrm{CEO}_{2}, \mathrm{CMRO}_{2}$ and the percentage change between these, before $\mathrm{CPB}$ and before and after DHCA in each animal. A repeated measures multivariate analysis of variance (MANOVA; SAS 6.12TS045; SAS Institute, Inc, Cary, NC) was used to compare variable means within each group. When the Wilks' Lambda statistic resulted in a probability value of less than .05 , multiple paired comparisons were made with a paired samples $t$ test to better identify the source of the difference. A factorial model analysis of variance was used to compare percentage reductions of blood flow to different brain regions after DHCA. Individual comparisons between regional means were performed with an unpaired (independent samples) $t$ test. An unpaired $t$ test was also used to compare variable means between the groups and to compare relative (percent) change in $\mathrm{CBF}, \mathrm{CDO}_{2}$, and $\mathrm{CMRO}_{2}$.

\section{Results}

Before CPB, regional and global CBF, CVR, cerebral oxygen handling, and RBF were similar in both the control and the LG6 groups (independent samples $t$ test; $P>$.18). No significant differences were detected between the 2 groups in cerebral perfusion pressure, nasopharyngeal temperature, arterial blood gases, $\mathrm{pH}$, hematocrit and hemoglobin at each measurement (independent samples $t$ test; $P>.10$, data not shown). Within each group, no significant differences were detected in cerebral perfusion pressure, nasopharyngeal temperature, arterial blood gases, and $\mathrm{pH}$ at all 3 time points (MANOVA; $P>.11$ ).

Effects of CPB. At the commencement of CPB the right atrial pressure in the control group fell from $2.3 \pm$ $0.7 \mathrm{~mm} \mathrm{Hg}$ to $0.2 \pm 0.1 \mathrm{~mm} \mathrm{Hg}(P=.0001)$. A similar drop occurred in the LG6 filter group. The systemic vascular resistance did not change significantly in either group, and the pump flow was not significantly different from the pre-CPB cardiac output. In the con- trol group, the hemoglobin level fell from $11.1 \pm 0.8$ $\mathrm{g} / \mathrm{dL}$ to $8.9 \pm 0.7 \mathrm{~g} / \mathrm{dL}(P=.0002)$, and the hematocrit level fell from $33.1 \% \pm 2.1 \%$ to $27.5 \% \pm 2.4 \%(P=$ .002 ) at the onset of CPB. Similar drops developed in the LG6 filter group. No significant difference in global or regional CBF, $\mathrm{CMRO}_{2}, \mathrm{CVR}$, or RBF was detected in either group at the onset of CPB compared with the pre-CPB values $(P>.06)$. Furthermore, no difference in these variables was detected between the groups $(P>.29)$.

Effects of DHCA on the brain. Sixty minutes of DHCA followed by 60 minutes of rewarming in the control group resulted in a significant fall in the systemic vascular resistance from $0.46 \pm 0.09 \mathrm{~mm} \mathrm{Hg} \cdot 100$ $\mathrm{gm} \cdot \mathrm{min} \cdot \mathrm{mL}^{-1}$ before DHCA to $0.35 \pm 0.05 \mathrm{~mm} \mathrm{Hg}$. $100 \mathrm{gm} \cdot \mathrm{min} \cdot \mathrm{mL}^{-1}$ after DHCA $(P=.01)$. As a result of this, the pump flow was increased from $131 \pm 24$ to $168 \pm 22 \mathrm{~mL} \cdot \mathrm{kg}^{-1} \cdot \mathrm{min}^{-1}(P=.01)$ to maintain the preset cerebral perfusion pressure of $50 \mathrm{~mm} \mathrm{Hg}$ at the time of CBF measurement. The sagittal sinus oxygen tension fell from $27.1 \pm 2.5 \mathrm{~mm} \mathrm{Hg}$ to $23.3 \pm 1.6 \mathrm{~mm}$ $\mathrm{Hg}$, and the sagittal sinus oxygen saturation fell from $42.7 \% \pm 6.5 \%$ to $26.0 \% \pm 5.5 \%$. These values were significantly lower than the levels before both CPB and DHCA $(P<.02)$. The sagittal sinus carbon dioxide tension increased after DHCA from $63.6 \pm 9.7 \mathrm{~mm} \mathrm{Hg}$ to $76.8 \pm 14.7 \mathrm{~mm} \mathrm{Hg}(P=.02)$, and the $\mathrm{pH}$ fell from 7.29 \pm 0.02 to $7.26 \pm 0.04(P=.05)$.

There was a significant reduction in blood flow to all regions of the brain in the control group after DHCA $(P$ $<$.004; Table I). Different brain regions were affected to different degrees. Recovery of blood flow was lowest in the cerebral hemispheres $(39.4 \% \pm 17.5 \%$ of preDHCA level) and greatest in the brain stem $(65.5 \% \pm$ $8.0 \% ; P<.05$; Fig 1$)$. The CVR rose significantly after DHCA $(P=.00003)$. The $\mathrm{CDO}_{2}$ and $\mathrm{CMRO}_{2}$ both fell to $47.7 \% \pm 12.6 \%$ and $60.1 \% \pm 11.3 \%$ of the preDHCA levels, respectively $(P=.001)$, and the $\mathrm{CEO}_{2}$ was significantly higher after DHCA $(P=.001$; Table II). RBF was significantly lower after DHCA, falling to $70.2 \% \pm 26.3 \%$ of the flow before DHCA $(P=.02)$.

Effects of a leukocyte-depleting filter. A similar pattern was seen in the LG6 filter group as in the control group in that 60 minutes of DHCA resulted in a fall in the systemic vascular resistance $(P=.02)$, with the need to increase the pump flow to maintain the cerebral perfusion pressure at $50 \mathrm{~mm} \mathrm{Hg}$. The sagittal sinus oxygen saturation fell from $38.4 \% \pm 5.3 \%$ to $27.4 \% \pm$ $7.2 \%(P=.04)$, and the sagittal sinus carbon dioxide tension rose from $58.1 \pm 8.4 \mathrm{~mm} \mathrm{Hg}$ to $67.4 \pm 5.0 \mathrm{~mm}$ $\mathrm{Hg}(P=.01)$. There was no significant difference after DHCA, however, in either sagittal sinus oxygen tension 


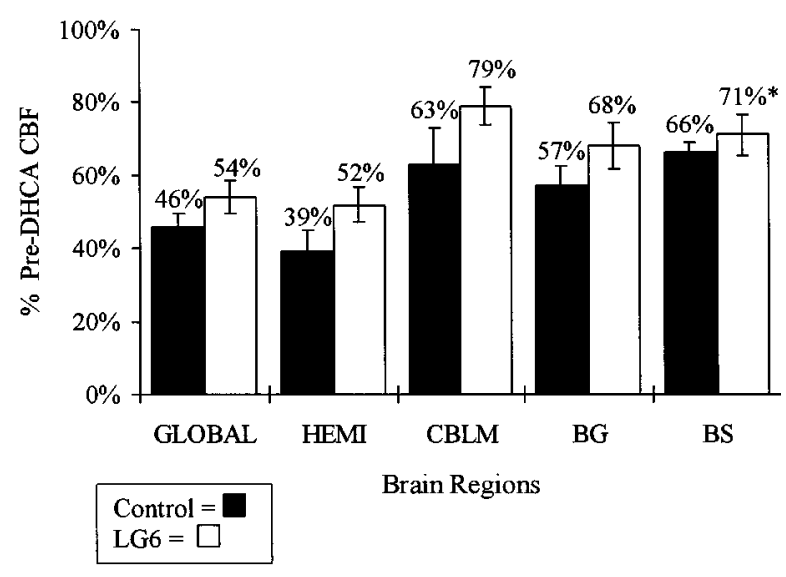

Fig 1. Global and regional $\mathrm{CBF}$ at 1 hour of reperfusion after 60 minutes of DHCA at $18^{\circ} \mathrm{C}$ in control and LG6 filter groups. Data are expressed as percentage of baseline $\mathrm{CBF}$ before DHCA. HEMI, Cerebral hemispheres; CBLM, cerebellum; $B G$, basal ganglia; $B S$, brain stem. *No significant difference between $\mathrm{CBF}$ before $\mathrm{CPB}$ and after DHCA within the group.

$(P=.09)$ or sagittal sinus $\mathrm{pH}(P=.13)$ compared with the pre-DHCA values.

There was also a significant reduction in $\mathrm{CBF}$ to all brain regions after DHCA, compared with the preDHCA value $(P<.01)$. The percentage recovery of CBF in the LG6 group was higher than in the control group after DHCA in all regions, but the difference did not reach significance $(P>.01$; Fig 1$)$. In the brain stem, however, no statistically significant difference was detected in CBF after DHCA when compared with the value before bypass $(P=.07)$. After DHCA in the LG6 filter group, the CVR was higher than the level before DHCA $(P=.001)$. The increase in CVR after DHCA was less than in the control animals, but the difference between the 2 groups did not reach significance (Fig 2). Although the fall in absolute $\mathrm{CDO}_{2}$ was less in the filter group than the control group and the percentage recovery in $\mathrm{CDO}_{2}$ to $55.2 \% \pm 13.0 \%$ of the preDHCA level was greater, neither difference reached statistical significance. The $\mathrm{CMRO}_{2}$ was also significantly lower after DHCA $(P=.01)$, falling to $66.0 \% \pm$ $22.3 \%$ of the pre-DHCA level. As with the $\mathrm{CDO}_{2}$, although the fall in absolute $\mathrm{CMRO}_{2}$ was less and the percentage recovery in $\mathrm{CMRO}_{2}$ was greater than the control group, neither difference reached significance. After DHCA, the RBF in the LG6 group fell to $81.0 \%$ $\pm 29.5 \%$ of the pre-DHCA value $(P=.06)$. Although there was no significant difference in RBF at any time point in the LG6 group, the improvement in RBF in the leukocyte filter group after DHCA was not significant-

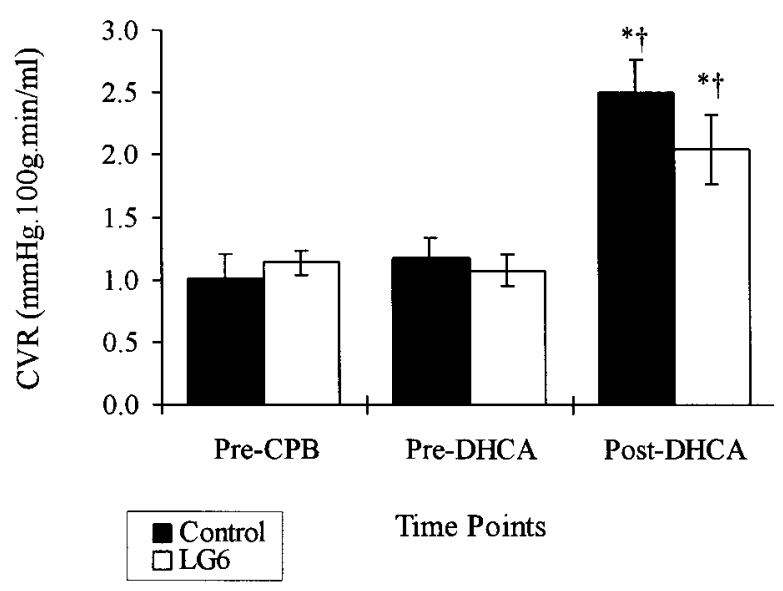

Fig 2. Mean cerebrovascular resistance in control and LG6 filter groups before CPB and before and after DHCA. PreDHCA, After commencement of CPB but before DHCA; Post-DHCA, after 60 minutes of DHCA at $18^{\circ} \mathrm{C}$ and $60 \mathrm{~min}-$ utes of rewarming. ${ }^{*}$ Significant difference from pre-CPB value within group; $P<.05$. 'Significant difference from preDHCA value within group; $P<.05$.

ly greater than the recovery to $70.2 \% \pm 26.3 \%$ in control animals $(P=.47)$.

\section{Discussion}

Cerebral ischemia is accompanied by an acute inflammatory response characterized by leukocyte infiltration and development of brain edema. ${ }^{4,14}$ It is now well established that neutrophils accumulate in the brain after both focal ${ }^{5,6}$ and global ${ }^{15,16}$ ischemia and that the increase in neutrophils is associated with neurologic damage. Neutrophils have been identified in microvessels as early as 30 minutes after the onset of ischemia, and the number of intravascular neutrophils seems to peak at about 12 hours. ${ }^{17}$ Parenchymal infiltration occurs slightly later but has been shown to begin as early as 6 hours after reperfusion, peaking at 24 to 48 hours. ${ }^{18}$ The early appearance of luminal leukocytes in ischemia suggests that these cells contribute to the genesis of ischemiareperfusion injury.

The current study shows that the establishment of normothermic CPB in the neonatal piglet is well tolerated and does not result in significant changes in cerebral hemodynamics. The significant drop in right atrial pressure at the onset of CPB indicates good venous drainage from the heart to the venous reservoir of the CPB circuit. The fall in hemoglobin and hematocrit levels is due to hemodilution caused by crystalloid in the CPB priming fluid. Both the control and the LG6 filter group showed a similar response to the com- 
Table I. Global and regional $C B F$ and RBF in control and LG6 filter groups before CPB and before and after DHCA

\begin{tabular}{llccc}
\hline Location & Group & Pre-CPB & Pre-DHCA & Post-DHCA \\
\hline Global CBF & Control & $54.9 \pm 16.1$ & $48.9 \pm 17.7$ & $21.9 \pm 8.7^{* \dagger}$ \\
& LG6 filter & $47.0 \pm 11.6$ & $50.6 \pm 15.1$ & $27.3 \pm 11.3^{* \dagger}$ \\
Hemispheres & Control & $42.1 \pm 12.1$ & $48.7 \pm 13.7$ & $18.3 \pm 7.9^{* \dagger}$ \\
& LG6 filter & $5.3 \pm 13.6$ & $41.5 \pm 12.6$ & $21.7 \pm 9.8^{* \dagger}$ \\
Cerebellum & Control & $48.4 \pm 13.4$ & $52.8 \pm 10.1$ & $31.5 \pm 7.6^{* \dagger}$ \\
& LG6 filter & $53.4 \pm 13.1$ & $47.3 \pm 8.6$ & $37.1 \pm 5.9^{* \dagger}$ \\
Basal ganglia & Control & $50.8 \pm 12.0$ & $43.7 \pm 10.4$ & $24.5 \pm 7.5^{* \dagger}$ \\
& LG6 filter & $43.0 \pm 10.9$ & $47.8 \pm 11.8$ & $31.6 \pm 7.2^{* \dagger}$ \\
Brain stem & Control & $46.1 \pm 11.8$ & $42.4 \pm 6.4$ & $27.5 \pm 5.1^{* \dagger}$ \\
& LG6 filter & $39.0 \pm 7.9$ & $46.7 \pm 10.7$ & $31.9 \pm 5.2^{\dagger}$ \\
Renal & Control & $144.5 \pm 33.3$ & $146.6 \pm 33.9$ & $103.6 \pm 20.5^{* \dagger}$ \\
& LG6 filter & $141.7 \pm 30.3$ & $146.1 \pm 34.7$ & $108.3 \pm 25.2$ \\
\hline
\end{tabular}

All values in units of milliliters $\cdot 100 \mathrm{~g}^{-1} \cdot \mathrm{min}^{-1}$.

${ }^{*}$ Significant difference from pre-CPB value within group (MANOVA, $P<.05$ ).

${ }^{\dagger}$ Significant difference from pre-DHCA value within group (MANOVA, $P<.05$ )

mencement of CPB. There were no significant changes between the 2 groups before DHCA.

After 60 minutes of DHCA at $18^{\circ} \mathrm{C}$ and 60 minutes of rewarming in the control group, the systemic vascular resistance level fell, and the pump flow was increased to maintain a constant cerebral perfusion pressure. The drop in the sagittal sinus oxygen tension, sagittal sinus oxygen saturation, and sagittal sinus $\mathrm{pH}$ and the rise in sagittal sinus carbon dioxide tension after DHCA reflect the increased oxygen extraction and the buildup of metabolites of anaerobic metabolism during ischemia. A drop in blood flow to all regions of the brain and to the kidneys followed DHCA. There was regional variation in CBF, however, with percentage recovery from the pre-DHCA level being greatest in the brain stem and lowest in the cerebral hemispheres. Because the arterial oxygen content was maintained at a constant level, the reduction in $\mathrm{CBF}$ was primarily responsible for the drop in $\mathrm{CDO}_{2}$. The combination of reduced $\mathrm{CBF}$ and increased $\mathrm{CEO}_{2}$ accounts for the fall in the $\mathrm{CMRO}_{2}$.

In the LG6 filter group, the pattern was similar to that in the control animals. The period of ischemia caused the drop in sagittal sinus oxygen saturation and the rise in sagittal sinus carbon dioxide tension after DHCA. In contrast with the control group, there was no significant difference in either sagittal sinus oxygen tension or sagittal sinus $\mathrm{pH}$ after DHCA; however, the $\mathrm{CEO}_{2}$ was still significantly higher than before DHCA. Interpretation of these results is not easy; it would seem that a trend toward improved recovery of sagittal sinus blood gases is present in the LG6 group compared with the control group. In the LG6 filter group, all the sagittal sinus blood gas variables are less impaired than in the control group after DHCA; however, the sagittal sinus oxygen tension and the sagittal sinus $\mathrm{pH}$ were the only variables not significantly impaired by comparison with the control group.

The CBF after DHCA in the LG6 group was significantly lower than the pre-DHCA value in all regions. It was also lower than the pre-CPB value in all regions except the brain stem, where the difference was not quite significant $(P=.07)$. The results may suggest a trend in the LG6 filter group toward greater recovery of regional and global CBF compared with the control group; the absolute values were higher than those in the control group in all regions, and the difference approached significance in the brain stem $(P=.08)$ and the basal ganglia $(P=.07)$. The percentage recovery from the pre-DHCA level was also higher in all brain regions but did not reach statistical significance. Although it is possible that a larger sample may result in a more convincing improvement in CBF after DHCA, the current study in the neonatal piglet does not really demonstrate any meaningful benefit. As in the control group, the $\mathrm{CDO}_{2}$ and $\mathrm{CMRO}_{2}$ were significantly lower and the CVR was significantly higher than the value before DHCA. Again, both the absolute and the relative differences were less in the LG6 group than the control group, but the differences did not reach statistical significance.

An improvement in CBF after cerebral ischemia has been demonstrated in studies in which neutrophilendothelial adhesion processes are disturbed. Immunodepletion of neutrophils or the use of ICAM-1 deficient mice in cerebral ischemia-reperfusion results in improved cortical CBF. ${ }^{5}$ After the use of monoclonal antibody to the leukocyte integrin CD18 in an immature piglet model of DHCA, improved regional blood flow to the brain stem, basal ganglia, and midbrain was shown early during reperfusion, but not later. ${ }^{19}$ 
Table II. Global cerebral oxygen handling and CVR in control and LG6 filter groups before CPB and before and after $D H C A$

\begin{tabular}{lllll}
\hline & Group & Pre-CPB & Pre-DHCA & Post-DHCA \\
\hline $\mathrm{CDO}_{2}\left(\mathrm{~mL} \cdot 100 \mathrm{~g}^{-1} \cdot \mathrm{min}^{-1}\right)$ & Control & $8.59 \pm 2.50$ & $6.24 \pm 2.31$ & $2.87 \pm 1.20^{* \dagger}$ \\
& LG6 filter & $7.43 \pm 1.95$ & $6.13 \pm 1.76$ & $3.38 \pm 1.36^{* \dagger}$ \\
$\mathrm{CMRO}_{2}\left(\mathrm{~mL} \cdot 100 \mathrm{~g}^{-1} \cdot \mathrm{min}^{-1}\right)$ & Control & $5.22 \pm 1.31$ & $3.64 \pm 1.34$ & $2.15 \pm 0.96^{* \dagger}$ \\
& LG6 filter & $4.63 \pm 1.02$ & $3.89 \pm 1.29$ & $2.47 \pm 1.04^{* \dagger}$ \\
$\mathrm{CEO}_{2}(\%)$ & Control & $61.3 \pm 3.7$ & $58.7 \pm 6.2$ & $74.7 \pm 5.3^{* \dagger}$ \\
& LG6 filter & $63.4 \pm 6.1$ & $62.8 \pm 4.8$ & $73.2 \pm 6.9^{* \dagger}$ \\
$\mathrm{CVR}\left(\mathrm{mm} \mathrm{Hg} \cdot 100 \mathrm{~g}^{-1} \cdot \mathrm{min}^{-1} \cdot \mathrm{mL}^{-1}\right)$ & Control & $1.02 \pm 0.51$ & $1.17 \pm 0.49$ & $2.50 \pm 0.77^{* \dagger}$ \\
& LG6 filter & $1.14 \pm 0.24$ & $1.08 \pm 0.37$ & $2.05 \pm 0.80^{* \dagger}$ \\
\hline
\end{tabular}

*Significant difference from pre-CPB value within group (MANOVA, $P<.05$ ).

${ }^{\dagger}$ Significant difference from pre-DHCA value within group (MANOVA, $P<.05$ ).

Whether adhesion of neutrophils represents a true hindrance to microvascular flow and thereby a reduction of $\mathrm{CBF}$ during cerebral ischemia-reperfusion injury remains uncertain. ${ }^{20}$

Statistically there was no significant difference at any time point in RBF in the leukocyte depletion group. When expressed as a percentage of the pre-DHCA value, however, the improvement in RBF in the leukocyte filter group after DHCA was not significantly greater than the recovery in control animals. A clinically significant benefit would therefore seem unlikely. Clinical evaluation of the LG6 filter has produced somewhat mixed results. Although some studies have concluded that leukocyte depletion should be used routinely in all children who undergo operations for cyanotic heart disease or extracorporeal membrane oxygenation, ${ }^{21}$ others have concluded no benefit. ${ }^{22,23}$ The potential benefits of leukocyte depletion do not only apply to the brain. The heart, lungs, and gut are all susceptible to ischemia-reperfusion injury that is mediated by activated neutrophils. Experiments suggest that mechanical leukocyte filtration may be advantageous in all these organs. With regard to post-CPB pulmonary function, a number of beneficial effects of leukocyte depletion have been reported. These include a reduction in ventilation time (and time in the intensive care unit), ${ }^{24}$ improved oxygenation, ${ }^{25}$ and reduced pulmonary edema and pulmonary vascular resistance. ${ }^{26}$

In a porcine model of neonatal cardiac surgery, mechanical leukocyte depletion significantly reduced the granulocyte count. This was associated with a reduction in leukocyte sequestration in the coronary vascular bed and a decrease in myocardial creatine kinase release and with improved postischemic recovery of left ventricular systolic function. ${ }^{27}$ Leukocyte depletion has also been shown to reduce the severity of reperfusion injury in the human small intestine. ${ }^{28}$

In conclusion, although the results with respect to all the $\mathrm{CBF}$ and metabolism variables measured were con- sistently better in the LG6 filter group than in the control group, the difference failed to reach statistical significance at the predetermined level of probability of less than .05. Use of a leukocyte-depleting filter failed to significantly affect cerebral and renal recovery after DHCA in the neonatal piglet model used in the current study. Accumulation of neutrophils in ischemic cerebral tissue, however, and the subsequent damaging effects of neutrophil activation continue for many hours after reperfusion. Neurobehavioral and histologic studies in survival models of DHCA will be necessary to determine these longer-term effects.

We thank Dr Lawrence H Muhlbaier, PhD, for the statistical analysis of the study and Ronnie Johnson for his expert technical help with the experiments.

\section{REFERENCES}

1. Hallenbeck JM, Dutka AJ, Tanishima T, Kochanek PM, Kumaroo KK, Thompson CB, et al. Polymorphonuclear leukocyte accumulation in brain regions with low blood flow during the early postischemic period. Stroke 1986;17:246-53.

2. Pozzilli C, Lenzi GL, Argentino C, Carolei A, Rasura M, Signore A, et al. Imaging of leukocytic infiltration in human cerebral infarcts. Stroke 1985;16:251-5.

3. del Zoppo GJ. Microvascular responses to cerebral ischemia/inflammation. Ann NY Acad Sci 1997;823:132-47.

4. Feuerstein GZ, Liu T, Barone FC. Cytokines, inflammation, and brain injury: role of tumor necrosis factor-alpha. Cerebrovasc Brain Metab Rev 1994;6:341-60.

5. Connolly ES Jr, Winfree CJ, Springer TA, Naka Y, Liao H, Yan $\mathrm{SD}$, et al. Cerebral protection in homozygous null ICAM-1 mice after middle cerebral artery occlusion: role of neutrophil adhesion in the pathogenesis of stroke. J Clin Invest 1996;97:209-16.

6. Matsuo Y, Onodera H, Shiga Y, Nakamura M, Ninomiya M, Kihara T, et al. Correlation between myeloperoxidase-quantified neutrophil accumulation and ischemic brain injury in the rat: effects of neutrophil depletion. Stroke 1994;25:1469-75.

7. Shiga Y, Onodera H, Kogure K, Yamasaki Y, Yashima Y, Syozuhara H, et al. Neutrophil as a mediator of ischemic edema formation in the brain. Neurosci Lett 1991;125:110-2.

8. Gourlay T, Fleming J, Taylor KM. Effects of pulsatile flow on the 
leucocyte depleting qualities of the LG-6 leucocyte depleting arterial line filter. Perfusion 1992;7:277-32.

9. Gourlay T, Fleming J, Taylor KM. Laboratory evaluation of the Pall LG-6 leucocyte depleting arterial line filter. Perfusion 1992;7:131-40.

10. Thurlow PJ, Doolan L, Sharp R, Sullivan M, Smith B, Andersen LW. Studies of the effect of Pall leucocyte filters LG6 and AV6 in an in vitro simulated extracorporeal circulatory system [published erratum appears in Perfusion 1996;11:38]. Perfusion 1995; 10:291-300.

11. Heymann MA, Payne BD, Hoffman JI, Rudolph AM. Blood flow measurements with radionuclide-labeled particles. Prog Cardiovasc Dis 1977;20:55-79.

12. Tsui SS, Kirshbom PM, Davies MJ, Jacobs MT, Greeley WJ, Kern FH, et al. Nitric oxide production affects cerebral perfusion and metabolism after deep hypothermic circulatory arrest. Ann Thorac Surg 1996;61:1699-707.

13. Tsui SL, Kirshbom PM, Davies MJ, Jacobs MT, Kern FH, Gaynor WJ, et al. Thromboxane A2-receptor blockade improves cerebral protection for deep hypothermic circulatory arrest. Eur J Cardiothorac Surg 1997;12:228-35.

14. Barone FC, Hillegass LM, Price WJ, White RF, Lee EV, Feuerstein GZ, et al. Polymorphonuclear leukocyte infiltration into cerebral focal ischemic tissue: myeloperoxidase activity assay and histologic verification. J Neurosci Res 1991;29:336-45.

15. Caceres MJ, Schleien CL, Kuluz JW, Gelman B, Dietrich WD. Early endothelial damage and leukocyte accumulation in piglet brains following cardiac arrest. Acta Neuropathol 1995;90:58291.

16. Gidday JM, Park TS, Gonzales ER, Beetsch JW. CD18-dependent leukocyte adherence and vascular injury in pig cerebral circulation after ischemia. Am J Physiol 1997;272(suppl):H2622-9.

17. Garcia JH, Liu KF, Yoshida Y, Lian J, Chen S, del Zoppo GJ. Influx of leukocytes and platelets in an evolving brain infarct (Wistar rat). Am J Pathol 1994;144:188-99.

18. Zhang RL, Chopp M, Chen H, Garcia JH. Temporal profile of ischemic tissue damage, neutrophil response, and vascular plug- ging following permanent and transient $(2 \mathrm{H})$ middle cerebral artery occlusion in the rat [published erratum appears in J Neurol Sci 1994;126:96]. J Neurol Sci 1994;125:3-10.

19. Aoki M, Jonas RA, Nomura F, Kawata H, Hickey PR. Anti-CD18 attenuates deleterious effects of cardiopulmonary bypass and hypothermic circulatory arrest in piglets. J Card Surg 1995;10(suppl):407-17.

20. Theilen H, Schrock H, Kuschinsky W. Gross persistence of capillary plasma perfusion after middle cerebral artery occlusion in the rat brain. J Cereb Blood Flow Metab 1994;14:1055-61.

21. Bolling KS, Halldorsson A, Allen BS, Rahman S, Wang T, Kronon M, et al. Prevention of the hypoxic reoxygenation injury with the use of a leukocyte-depleting filter. J Thorac Cardiovasc Surg 1997;113:1081-9.

22. Englander R, Cardarelli MG. Efficacy of leukocyte filters in the bypass circuit for infants undergoing cardiac operations. Ann Thorac Surg 1995;60(suppl):S533-5.

23. Lust RM, Bode AP, Yang L, Hodges W, Chitwood WR Jr. In-line leukocyte filtration during bypass: clinical results from a randomized prospective trial. ASAIO J 1996;42:M819-22.

24. Palanzo DA, Manley NJ, Montesano RM, Yiesley GL, Fordon D. Clinical evaluation of the LeukoGuard (LG6) arterial line filter for routine open heart surgery. Perfusion 1993;8:489-96.

25. Johnson D, Thomson D, Mycyk T, Burbridge B, Mayers I. Depletion of neutrophils by filter during aortocoronary bypass surgery transiently improves postoperative cardiorespiratory status. Chest 1995;107:1253-9.

26. Bando K, Pillai R, Cameron DE, Brawn JD, Winkelstein JA, Hutchins GM, et al. Leukocyte depletion ameliorates free radical-mediated lung injury after cardiopulmonary bypass. J Thorac Cardiovasc Surg 1990;99:873-7.

27. Wilson IC, DiNatale JM, Gillinov AM, Curtis WE, Cameron DE, Gardner TJ. Leukocyte depletion in a neonatal model of cardiac surgery. Ann Thorac Surg 1993;55:12-9.

28. Sisley AC, Desai T, Harig JM, Gewertz BL. Neutrophil depletion attenuates human intestinal reperfusion injury. J Surg Res 1994;57:192-6. 